\title{
DESIGNING AND MODELLING COAST MANAGEMENT GIS FOR BOSPHORUS
}

\author{
M. U. Gumusay a, ${ }^{*}$, O. Ozdemir ${ }^{b}$, T. Bakirman ${ }^{\text {a }}$ \\ a YTU, Civil Engineering Faculty, 34220 Esenler Istanbul, Turkey - (gumusay, bakirman)@yildiz.edu.tr \\ b Olcum Muhendislik, 48700, Marmaris, Muğla, Turkey - osmanozdemir105@gmail.com
}

Commission IV, WG IV/5

KEY WORDS: Web Based GIS, Bosphorus, Georeferencing, DTM, Digitizing

\begin{abstract}
:
Web based geographic information systems (GIS) has great potential based on developments in internet and web technology. Web based GIS is a network based tool that takes advantage of internet with visualizing, analysing and accessing of distributed data and analysis functions. With the length of 30 kilometres, the Bosphorus provides an essential zone that offers great maritime traffic services. This shipping way which connects The Black Sea and The Mediterranean Sea through The Marmara Sea, has no alternative and it is substantial for economies of Black Sea countries. The Bosphorus is one of most important natural straits in the world handling 150 transit ships, 23 freighters with dangerous cargo and 2500 local transport ships with 2 million passengers on daily basis. In this study, it is aimed to create a web based GIS application for an effective coast management which includes berthing factors (anchorage areas, currents, submerged, etc.), maritime traffic factors (traffic separation schemes, traffic flow directions), closed areas and other factors (lighthouses, buoys, beacons, etc.) by digitizing printed navigation charts produced by Turkish Naval Forces, Office of Navigation, Hydrography and Oceanography.
\end{abstract}

\section{INTRODUCTION}

Management of the coastal zone is an essential issue due to the growing social, demographic and touristic activities and pressures that threaten its long-term sustainability (Moore et al., 1999). Any developmental activity in the coastal zone requires a clear understanding of the processes controlling coastal stability and persistence (Noujas et al., 2016). In order to practice effective coastal management system, scientists need to understand the way the natural environment and human activities are interconnected to form a system. Key aspects of the system includes four main subjects which are biological (ecosystem, species diversity, etc.), physical (topography, geology, sea levels, etc.), socio-economic (human activities, land use, etc.) and legal (resource use right, law and regulations) (Bartlett and Smith, 2004). The system consists of various topics so it needs a multi-disciplinary approach.

Coastal planning and management relied mainly on field observations and historical data. With the rapid development of computers, information and surveying technologies, geographic information systems (GIS) have revolutionized our ability to understand complex data series, interaction of coastal processes and to manage the resources of the coastal zone more effectively (Mayerle et al., 2016). The need for integration and management of all the factors and aspects related to the coastal zone requires GIS to deal with the current tasks (Rodríguez et al., 2009).

The Bosphorus is one of the busiest and narrowest water channels of the world that provides an essential zone offering great maritime traffic services. It is one of the substantial shipping way that connects the countries in the north of Black Sea and the countries of the Mediterranean for centuries, which situated in the middle of an important commerce, industry, transportation and tourism centre around where 15 million people live (Tasligil, 2004). The Bosphorus is one of most important natural straits in the world handling 150 transit ships, 23 freighters with dangerous cargo and 2500 local transport ships with 2 million passenger on daily basis.

In this study, it aimed to create a Web Based Istanbul Bosphorus GIS with physical and biological components of coast management system to aid military and civil sailors underway, which consists of information about berthing factors (anchorage grounds, depth, sedimentation, currents and submerged etc.), maritime traffic items (traffic separation schemes, traffic flow directions), closed areas, points of interest in sea surface for both sailing and berthing (lighthouse, buoy, beacon) and points of interests in land (radars, elevation points) which were derived by digitizing navigation charts produced by Turkish Naval Forces Office of Navigation, Hydrography and Oceanography.

\section{METHODOLOGY}

The Bosphorus provides marine traffic service area with the length of 31 kilometres. The width considered as the distance between Anatolia and Rumeli Lighthouse in the north entrance of the strait is 3600 meters. Generally the strait is wider in the northern are and it gets narrower as heading to the south. The narrowest distance in the strait is 698 meters in between Emirgan and Kanlica towns (Tasligil, 2004).

The strait has no alternative for sailing from Black Sea to Mediterranean through Marmara Sea and it is also substantial for economies of Black Sea countries. Additionally and most importantly, the residents may face great danger that may be caused by dense maritime traffic in any second. Thus, it is certain that it must be benefited from web based GIS technologies for Bosphorus which has such a significant location and maritime traffic.

\footnotetext{
* Corresponding Author
} 
The internet changes the way to access, share and distribute information. In this way, it also changes GIS analysis and visualization methods. Web based GIS tools rapidly develop as internet and web technologies improve. Web based GIS, is a GIS tool that uses the internet to access and execute distributed data, analyses and visualizing functions (Sahin and Gumusay, 2007).

Web based GIS uses client server architecture for GIS analysis. Necessary processes are distributed between client and server. The client requests data and analysis functions from the server. The server completes the request and transmits the response or provides data and analysis functions to the client (Peng, 1999). Web based GIS is an interactive system that provides connection with Internet. Web based GIS is a distributed system that it can access data and applications in other computers in a network using internet connection. This system does not require client to have data or application as they are provided by the server once a request is made. Web based GIS is a dynamic system since data and applications are provided by the server, clients are always dynamically kept up to date with the latest information (Fu and Sun, 2010).

In this study, ArcGIS for Server and ArcGIS Online software have been used to create web services and web based GIS applications. ArcGIS for Server software creates web services that can be accessed by various ArcGIS platforms and thirdparty clients (Figure 1). ArcGIS Online is an online platform that provides mapping service where end user can create web maps and web applications (Figure 2). Thus, mentioned integrated systems approach creates a user-friendly environment (Law, 2013).

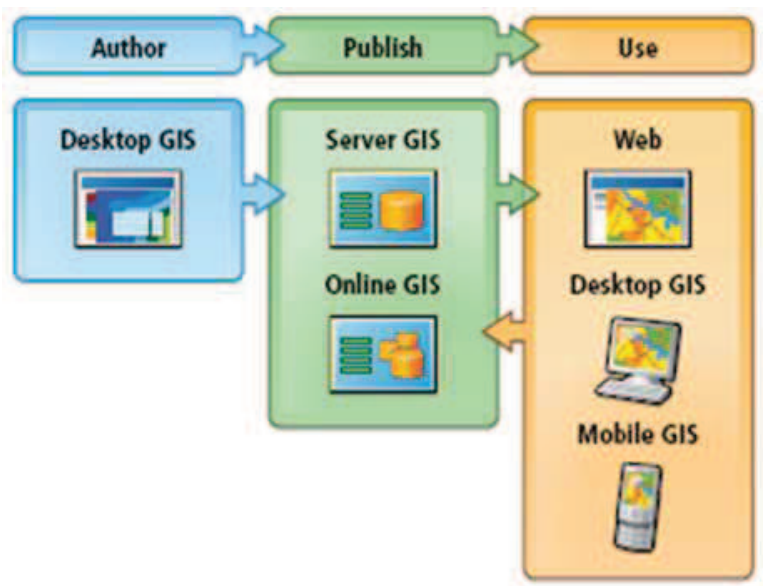

Figure 1. Desktop to web workflow

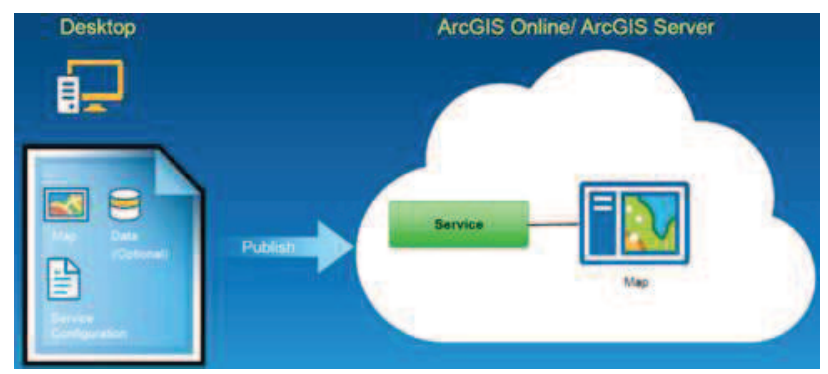

Figure 2. Creating web map

\section{SYSTEM DESIGN AND MODELLING}

Base data source used in this study are navigation charts in different scales such as 1:60000, 1:50000, 1:30000 and 1:12500 produced by Turkish Naval Forces Office of Navigation, Hydrography and Oceanography. Maritime traffic separation schemes, flow directions and flow regulations, sea floor sedimentation, lighthouses, buoys, beacons, sea floor depths, rocks and other symbols for navigation are to be found in navigation charts.

\subsection{Lighthouses}

Lighthouses aid sea vehicles to locate position and direction and they can be in different shapes and forms. The abbreviation used for different lighthouses in navigation charts are listed in Table 1 and the symbology of a lighthouse can be viewed in Figure 3.

\begin{tabular}{|l|l|}
\hline $\begin{array}{l}\text { Abbreviation } \\
\text { International }\end{array}$ & Class of light \\
\hline F & Fixed \\
\hline FI & Single-flashing \\
\hline FFI & Fixed and Flashing \\
\hline LFI & Long-flashing \\
\hline W; G; R; Y & W: White; G: Green; R: Red; Y:Yellow \\
\hline Sec & Second \\
\hline $\mathrm{M}$. & Mil \\
\hline $\mathrm{m}$ & Meter \\
\hline $\mathrm{Q}_{\mathrm{k}}$ & Continuous quick \\
\hline $\mathrm{IQ}$ & Interrupted quick \\
\hline
\end{tabular}

Table 1. Lighthouse abbreviations

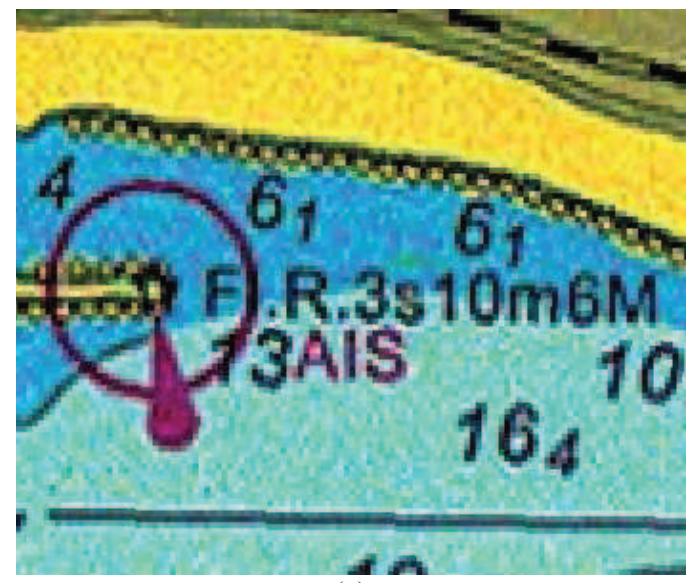

(a)

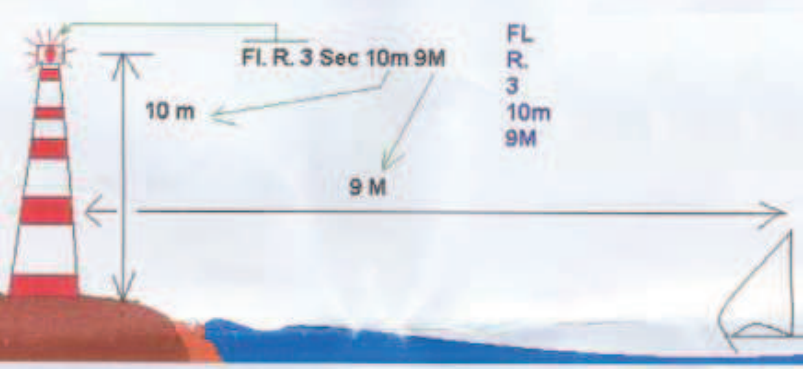

(b)

Figure 3. (a) Lighthouse symbology, (b) Abbreviation (FL= Flashing, $\mathrm{R}=$ Red (colour), 3 seconds (interval), 10 meters (height), 9 meters (range)) 


\subsection{Buoys and Beacons}

Buoys and beacons equipment are used to mark a zone (submerged area), aid berthing and sailing. Buoys are usually placed at the entrance of ports and since they are connected to sea floor, their position is fixed. Buoys can be found in different shapes such as minor light floats, mooring buoys and special purpose buoys. Symbology of buoys and beacons can be seen in Figure 4.

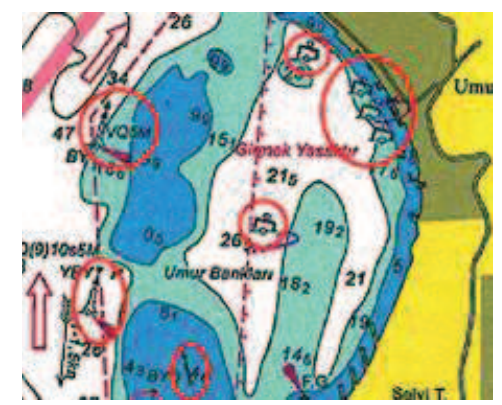

Figure 4. Symbology of buoys and beacons

\subsection{Rocks, Wrecks, Obstructions}

Rocks, wrecks and obstructions which are dangerous for sailors are shown in navigation charts. 4 types of presentation is available for this class (Table 2). There are rocks, wrecks and obstructions in 104 points in Bosphorus.

\begin{tabular}{|c|c|l|}
\hline GIS Symbol & Map Symbol & \multicolumn{1}{c|}{ Information } \\
\hline & $\begin{array}{l}\text { Wreck showing any } \\
\text { portion of hull or } \\
\text { super-structure at level } \\
\text { of chart datum }\end{array}$ \\
\hline 2 & $\begin{array}{l}\text { Wreck, least depth } \\
\text { known by sounding } \\
\text { only }\end{array}$ \\
\hline 3 & $\begin{array}{l}\text { The wrecks thus } \\
\text { represented are than } \\
\text { potentially dangerous } \\
\text { to vessels with a } \\
\text { draught greater than 20 } \\
\text { m }\end{array}$ & $\begin{array}{l}\text { Wreck, least depth } \\
\text { unknown, considered } \\
\text { to be potentially } \\
\text { dangerous to some } \\
\text { surface vessels }\end{array}$ \\
\hline
\end{tabular}

Table 2. Rocks, wrecks and obstructions symbols

\subsection{Seabed Sedimentation}

Seabed sedimentation information which is essential during anchoring is provided in the maps. Anchoring technique and anchor type depend on the sea floor properties as it would not be safe to anchor in rushes or it would damage biodiversity to anchor in coral area. Table 3 shows types of seabed sedimentation and symbology.

\begin{tabular}{|c|l|c|l|}
\hline Abb. & & Abb. & \\
\hline $\mathrm{S}$ & Sand & $\mathrm{P}$ & Pebbles \\
\hline $\mathrm{M}$ & Mud & $\mathrm{Cb}$ & Cobbles \\
\hline $\mathrm{Cy}$ & Clay & $\mathrm{R}$ & Rock, Rocky \\
\hline $\mathrm{Si}$ & Silt & Bo & Boulders \\
\hline $\mathrm{St}$ & Stones & Co & Coral \\
\hline $\mathrm{G}$ & Gravel & $\mathrm{M}$, & Mud and Shells \\
& & Sh & \\
\hline $\mathrm{Sh}$ & Shells & $\mathrm{Wd}$ & Rushes, moss \\
\hline $\mathrm{S} / \mathrm{M}$ & Ex: Mud, Sand & & \\
\hline & & & \\
& & &
\end{tabular}

Table 3. Seabed sedimentation abbreviations and symbology

\subsection{Tides and Currents}

Tides and currents are shown in restricted areas. 14 tides and current features are collected from Bosphorus navigation charts (Table 4).

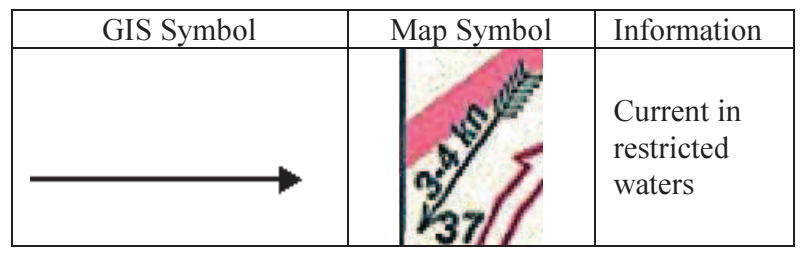

Table 4. Tides and currents symbology

\subsection{Tracks and Routes}

Maritime traffic separation scheme, traffic flow directions, port entrances and channels are presented in maps where density of maritime traffic is high, using International Maritime Organization's (IMO) standards (Table 5).

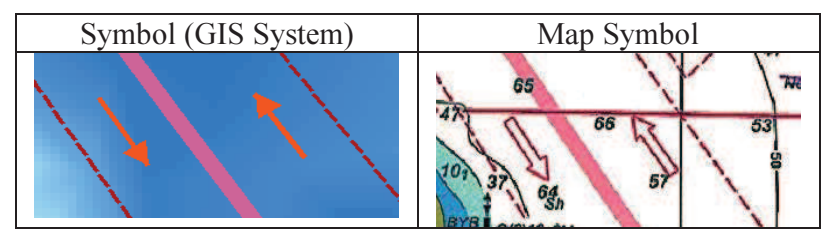

Table 5. Tracks and routes symbology. Established (mandatory) direction of traffic flow. Separation line (large-scale, smaller scale).

\subsection{Zones}

Anchoring and prohibited military zones, anchoring and training areas are presented in navigation charts. 


\subsection{Energy Transmission Lines}

Power transmission lines, radio station lines, submarine lines and line protection areas are marked on navigation charts.

\subsection{Sea Depth}

Sea depth points presented in navigation charts can be seen in Table 6 . These points are shown as values without any points or markings.

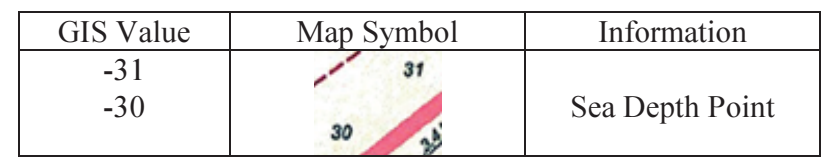

Table 6. Sea depth points

\subsection{Points of Interests in Land}

Various of structures in land such as settlements, spot height, chapels, sirens, radar points, radio and TV towers, bridges, transportation lines, hospitals, stadiums etc. are shown in navigation charts.

\subsection{Layer and Attribute Design}

The design of each layers and attributes that are used in the system is given in Table 7 .

Layer of Lights Design
\begin{tabular}{|l|l|l|c|l|}
\hline Layer Design \\
\hline Feature Class Name & Layer Name & Geometry Type \\
\hline Lights & Lights & Point \\
\hline \multicolumn{5}{|l|}{} \\
\hline Attribute Design & Alias & Type & Length & Sample Data \\
\hline Name & Name of Light & String & 50 & Rumeli Light (Türkeli) \\
\hline NameOfLight & Properties & String & 25 & FI(2)12s58m18M \\
\hline Properties & Label & String & 10 & Pilon \\
\hline Label & Information & String & 50 & Horn 20s (Fog light) \\
\hline Information
\end{tabular}

Layer of Buoys and Beacons Design

\begin{tabular}{|l|l|l|l|l|}
\hline Layer Design \\
\hline Feature Class Name & Layer Name & Geometry Type \\
\hline BuoysAndBeacons & Buoys and Beacons & Point \\
\hline \multicolumn{5}{|l|}{} \\
\hline Attribute Design & Alias & Type & Length & Sample Data \\
\hline Name & Buoy/Beacon & String & 20 & Beacons \\
\hline BuoyBeacon & Information & String & 25 & $\mathrm{Q}(6)+$ LFI15s,YB,AIS \\
\hline Information
\end{tabular}

Layer of Rocks, Wrecks Obstruction Design

\begin{tabular}{|l|l|l|}
\hline Layer Design \\
\hline Feature Class Name & Layer Name & Geometry Type \\
\hline
\end{tabular}

\begin{tabular}{|l|l|l|}
\hline RocksWrecksObsruction & Rocks Wrecks Obstruction & Point \\
\hline
\end{tabular}

\begin{tabular}{|l|l|l|l|}
\hline \multicolumn{5}{|l|}{$\mid$} \\
\hline Attribute Design & Alias & Type Length & Sample Data \\
\hline Name & Type & Short Integer & 2 \\
\hline Type & Depth & Float & 38 \\
\hline Depth & Information & Text 115 & \\
\hline Information &
\end{tabular}

Layer of Nature of the Seabed Design

\begin{tabular}{|c|c|c|c|c|}
\hline \multicolumn{5}{|l|}{ Layer Design } \\
\hline Feature Class Name & Layer Name & \multicolumn{3}{|c|}{ Geometry Type } \\
\hline NatureOfSeabed & $\begin{array}{l}\text { Nature of the } \\
\text { Seabed }\end{array}$ & \multicolumn{3}{|l|}{ Point } \\
\hline \multicolumn{5}{|l|}{ Attribute Design } \\
\hline Name & Alias & Type & Length & Sample Data \\
\hline Label & Label & String & 10 & Si.S \\
\hline NatureSeabed & $\begin{array}{l}\text { Nature of the } \\
\text { Seabed }\end{array}$ & String & 35 & Silt, Sand \\
\hline
\end{tabular}

Table 7. Design of layers and attributes

\begin{tabular}{|c|c|c|c|c|}
\hline \multicolumn{5}{|l|}{ Layer Design } \\
\hline Feature Class Name & Layer Name & \multicolumn{3}{|c|}{ Geometry Type } \\
\hline Current & \begin{tabular}{|l} 
Direction of \\
Current
\end{tabular} & \multicolumn{3}{|l|}{ Line } \\
\hline \multicolumn{5}{|l|}{ Attribute Design } \\
\hline Name & Alias & Type & Length & Sample Data \\
\hline Rates & Rates & String & 10 & $1,5-2 \mathrm{Kn}$ \\
\hline Information & Information & String & 50 & $\begin{array}{l}\text { Current in restricted } \\
\text { waters }\end{array}$ \\
\hline
\end{tabular}

Layer of Ferry Quay Design

\begin{tabular}{|l|l|l|l|l|}
\hline Layer Design \\
\hline Feature Class Name & Layer Name & Geometry Type \\
\hline FerryQuay & Ferry Quay & Point \\
\hline \multicolumn{5}{|l|}{} \\
\hline Attribute Design & Alias & Type & Length & Sample Data \\
\hline Name & Fery Quay Name & String & 50 & -38 \\
\hline FeryQuayName & TimeTable & String & 200 & \\
\hline TimeTable &
\end{tabular}

Layer of Fog Signal Design

Layer of Fog Signal Design
\begin{tabular}{|l|l|l|l|l|}
\hline Layer Design \\
\hline Feature Class Name & Layer Name & Geometry Type \\
\hline FogSignal & Fog Signal & Point \\
\hline & Length & Sample Data \\
\hline Attribute Design & Alias & Type & 15 & $(2) 20$ s \\
\hline Name & Information & String & 15 & Siren \\
\hline Information & Label & String & 6 & \\
\hline Label
\end{tabular}

Layer of Radar Points Design

Layer of Radar Points Design
\begin{tabular}{|l|l|l|l|l|}
\hline Layer Design \\
\hline Feature Class Name & Layer Name & Geometry Type \\
\hline RadarPoints & Radar Points & Point \\
\hline & Attribute Design & Type & Length & Sample Data \\
\hline Name & Name & String & 15 & Radar Tr. \\
\hline Name & Information & String & 20 & Radar Points \\
\hline Information
\end{tabular}

Layer of Radio Television Tower Design
\begin{tabular}{|l|l|l|l|l|}
\hline Layer Design \\
\hline Feature Class Name & Layer Name & Geometry Type \\
\hline RadioTelevisionTower & \multicolumn{2}{|c|}{ Radio Television Tower } & Point \\
\hline \multicolumn{5}{|l|}{} \\
\hline Attribute Design & Alias & Type & Length & Sample Data \\
\hline Name & Description & String & 30 & Radio, Television Mast \\
\hline Description & Label & String & 10 & Tv.Tr. \\
\hline Label
\end{tabular}

Layer of Bridges, Tube and Rail Tube Tunnel Design

\begin{tabular}{|l|l|l|l|l|}
\hline Layer Design & \multicolumn{3}{l|}{ Geometry Type } \\
\hline Feature Class Name & Layer Name & Line \\
\hline BridgeTupeMamararay & \multicolumn{4}{|l|}{ Bridges, Tube and Rail Tube Tunnel } \\
\hline \multicolumn{4}{|l|}{} \\
\hline Attribute Design & Alias & Type & Length & Sample Data \\
\hline Name & Name & String & 50 & Boğaziçi Bridge \\
\hline Name
\end{tabular}

Layer of Anchoring Area Design

\begin{tabular}{|c|c|c|c|c|}
\hline \multicolumn{5}{|l|}{ Layer Design } \\
\hline Feature Class Name & \multicolumn{2}{|c|}{ Layer Name } & \multicolumn{2}{|c|}{ Geometry Type } \\
\hline AnchoringArea & \multicolumn{2}{|c|}{ Anchoring Area } & \multicolumn{2}{|c|}{ Polygon } \\
\hline \multicolumn{5}{|l|}{ Attribute Design } \\
\hline Name & Alias & Type & Length & Sample Data \\
\hline Information & Information & String & 50 & Passenger Ship \\
\hline
\end{tabular}

\begin{tabular}{|c|c|c|c|c|}
\hline \multicolumn{5}{|l|}{ Layer Design } \\
\hline Feature Class Name & Layer Name & \multicolumn{3}{|c|}{ Geometry Type } \\
\hline $\begin{array}{l}\text { HighVoltageTransmission } \\
\text { Line }\end{array}$ & $\begin{array}{l}\text { High-Voltage } \\
\text { Transmission }\end{array}$ & \multicolumn{3}{|l|}{ Line } \\
\hline \multicolumn{5}{|l|}{ Attribute Design } \\
\hline Name & Alias & Type & Length & Sample Data \\
\hline Information & Information & String & 50 & $66 \mathrm{~m}$ above sea level \\
\hline AddInformation & Add Information & String & 50 & $\begin{array}{l}\text { High-Voltage } \\
\text { Transmission }\end{array}$ \\
\hline
\end{tabular}

Table 7. Cont. Design of layers and attributes 


Layer of Submarine Cables Design
\begin{tabular}{|l|l|l|l|l|}
\hline Layer Design & Layer Name & Geometry Type \\
\hline Feature Class Name & Length & Sample Data \\
\hline SubmarineCables & Submarine Cables & Line \\
\hline \multicolumn{5}{|l|}{} \\
\hline Attribute Design & Alias & Type & 10 & $1232 \mathrm{~m}$ \\
\hline Name & Cable Distance & String & 50 & Sabmarine Cable \\
\hline LineDistance & Information & String & 50 & \\
\hline Information & & & \\
\hline
\end{tabular}

\begin{tabular}{|c|c|c|c|c|}
\hline \multicolumn{5}{|c|}{ Layer of Sea Depth Point Design } \\
\hline \multicolumn{5}{|c|}{ Layer Design } \\
\hline Feature Class Name & Layer Name & \multicolumn{3}{|l|}{ Geometry Type } \\
\hline SeaDephtPoint & Sea Depht Point & \multicolumn{3}{|l|}{ Point } \\
\hline \multicolumn{5}{|l|}{ Attribute Design } \\
\hline Name & Alias & Type & Length & Sample Data \\
\hline SeaDephtPoint & Sea Depht Point & Float & & -38 \\
\hline
\end{tabular}

\begin{tabular}{|c|c|c|c|c|}
\hline \multicolumn{5}{|l|}{ Layer Design } \\
\hline Feature Class Name & Layer Name & \multicolumn{3}{|c|}{ Geometry Type } \\
\hline \begin{tabular}{|l|} 
CorrelatePoint \\
\end{tabular} & Correlate Point & \multicolumn{3}{|c|}{ Point } \\
\hline \multicolumn{5}{|l|}{\begin{tabular}{|l|} 
Attribute Design \\
\end{tabular}} \\
\hline Name & Alias & Type & Length & Sample Data \\
\hline PointNumber & Point Number & String & 20 & Coralete Point 1 \\
\hline
\end{tabular}

Table 7. Cont. Design of layers and attributes

\section{WEB BASED GIS APPLICATION}

All navigation charts have been imported into GIS environment and georeferencing has been performed for each map. Total of 3032 features have been digitized in accordance with layer designs (Table 8).

\begin{tabular}{|c|c|c|c|}
\hline Layer Name & $\begin{array}{l}\text { Number of } \\
\text { Digitizing } \\
\text { Item }\end{array}$ & Layer Name & $\begin{array}{c}\text { Number of } \\
\text { Digitizing } \\
\text { Item }\end{array}$ \\
\hline Lights & 43 & Depth of Sea & 2349 \\
\hline $\begin{array}{l}\text { Buoys and } \\
\text { Beacons }\end{array}$ & 45 & $\begin{array}{l}\text { Rocks Wrecks } \\
\text { Obstruction }\end{array}$ & 104 \\
\hline $\begin{array}{l}\text { Nature of } \\
\text { the Seabed }\end{array}$ & 46 & $\begin{array}{l}\text { Direction of } \\
\text { Current }\end{array}$ & 23 \\
\hline $\begin{array}{l}\text { Traffic } \\
\text { Direction of } \\
\text { Flow }\end{array}$ & 46 & $\begin{array}{l}\text { Traffic } \\
\text { Separator }\end{array}$ & 2 \\
\hline $\begin{array}{l}\text { Traffic } \\
\text { Boundary }\end{array}$ & 7 & $\begin{array}{l}\text { Military } \\
\text { Training Area }\end{array}$ & 1 \\
\hline $\begin{array}{l}\text { Anchoring } \\
\text { Area }\end{array}$ & 2 & Forbidden Line & 9 \\
\hline $\begin{array}{l}\text { Forbidden } \\
\text { Zone }\end{array}$ & 4 & $\begin{array}{l}\text { High-Voltage } \\
\text { Transmission }\end{array}$ & 2 \\
\hline $\begin{array}{l}\text { Submarine } \\
\text { Cables }\end{array}$ & 7 & $\begin{array}{l}\text { Submarine } \\
\text { Cable Area }\end{array}$ & 2 \\
\hline Chimney & 3 & Fog Signals & 1 \\
\hline $\begin{array}{l}\text { Radio } \\
\text { Television } \\
\text { Tower }\end{array}$ & 7 & Prayer Place & 80 \\
\hline $\begin{array}{l}\text { Land } \\
\text { Elevation } \\
\text { Point }\end{array}$ & 44 & Radar Points & 7 \\
\hline Ferry Quay & 48 & $\begin{array}{l}\text { Settlement } \\
\text { Centres }\end{array}$ & 102 \\
\hline Building & 30 & $\begin{array}{l}\text { Bridges, Tube } \\
\text { and Rail Tube } \\
\text { Tunnel }\end{array}$ & 17 \\
\hline GS Island & 1 & & \\
\hline
\end{tabular}

Table 8. Digitized layer feature counts
In order to acquire topography of the seafloor, a digital terrain model has been produced using sea depth points by performing ANUDEM (Hutchinson, 2011). Seafloor topography of Bosphorus can be seen in Figure 5.

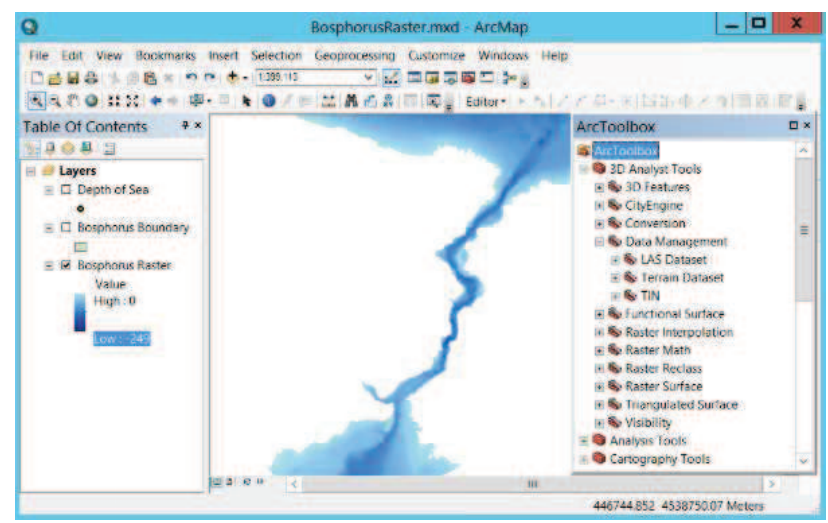

Figure 5. Seafloor topography

Web based GIS application have been developed using Web AppBuilder interface. In order to create an application in Web AppBuilder, created geographic database must be shared as service using ArcGIS Server or cloud. Therefore, once integration and analysis are performed, all data have been published as web services.

Search and query widgets have been created using Web AppBuilder to provide end-users ability to find detailed information (Figure 6).

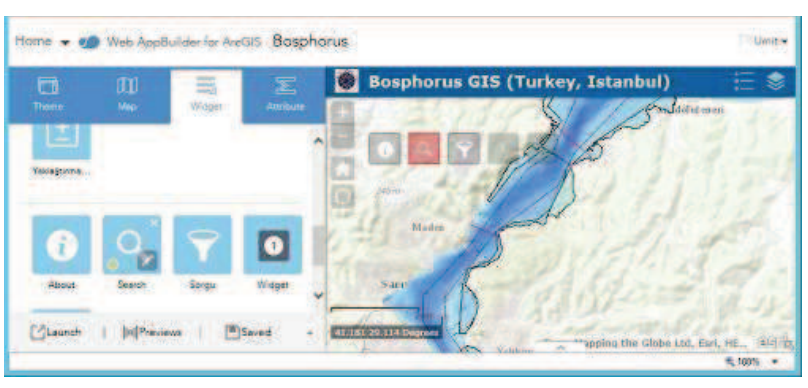

Figure 6. Widget design

PC and mobile compatible versions of web application have been created separately since orientation and resolution need to be suitable for both devices. Web based GIS application can be accessed using this link: www.gis.yildiz.edu.tr/webservices.html Final look of the web application can be seen in Figure 7.

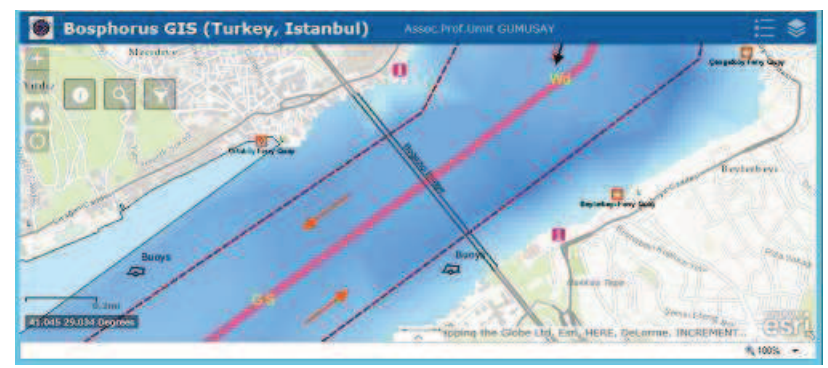

Figure 7. Web based GIS application

Users can search and query all the features in the system such as piers, lighthouses, currents etc. Lighthouses play a key role for sailing during night. So, created system allows users to query location and information about lighthouses or any other features in the web application. Sample queries can be seen in Figure 8 . 


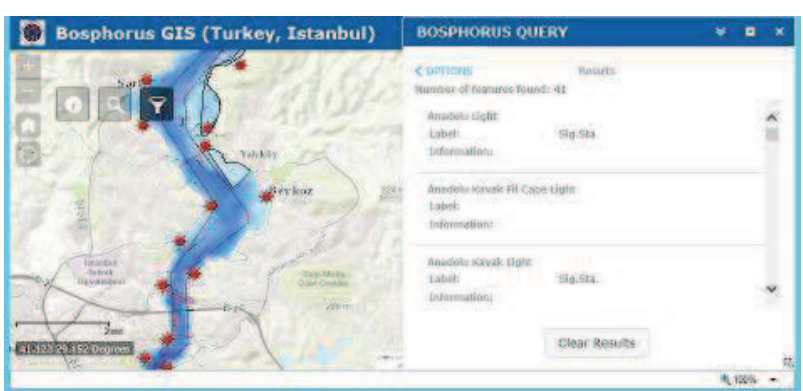

(a)

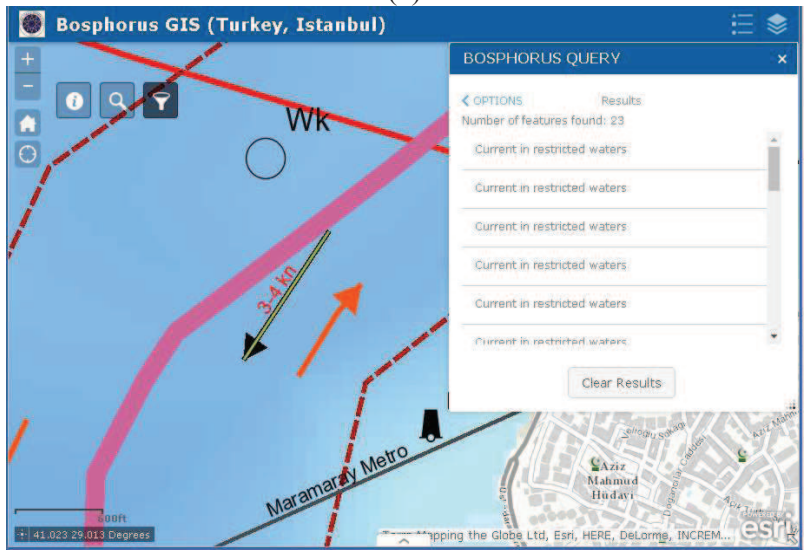

(b)

Figure 8. (a) Lighthouse query, (b) Current query

Mobile compatibility of the created application has been tested using Apple iPhone 5. The system has the ability to locate the user's location using mobile device's GPS (Figure 9).

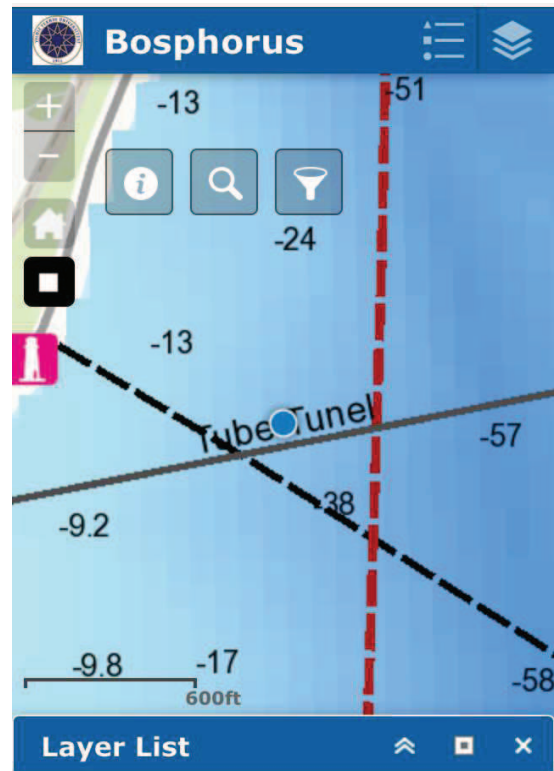

Figure 9. GPS location of user in the application

\section{RESULTS}

In this study, a web based coastal management GIS application of Bosphorus with physical and biological components of coast management system have designed and developed using ArcGIS Online. Designed system allows users to obtain detailed information about anchorage grounds, depth, sedimentation, currents, wrecks, traffic separation schemes, traffic flow directions, closed areas, lighthouses, buoys, beacons and points of interests in land along Bosphorus coast and sea. ArcGIS
Online and Web AppBuilder interfaces which were used to create this web application allows users to rapidly create web services and web mapping applications.

Web based geographic information system are being widely used through the developments of mobile, internet and web technologies. Widespread use of web GIS makes daily life easier and practical. Consequently, developing integrated coastal zone management processes for cities along shoreline with the help GIS and web technologies will yield the problems relate to management of resources, sustainability of sea and marine protected areas.

\section{ACKNOWLEDGEMENTS}

Georeferencing and digitizing processes of this study has been carried out in the framework of a bachelor thesis.

\section{REFERENCES}

Bartlett, D., Smith, J., 2004. GIS for coastal zone management. CRC press.

Fu, P., Sun, J., 2010. Web GIS: principles and applications. Esri Press.

Hutchinson, M.F., 2011. "ANUDEM version 5.3, user guide" Canberra: Fenner School of Environment and Society, Australian National University, http://fennerschool.anu.edu.au/files/usedem53_pdf_16552.pdf (13.04.2016).

Law, D., 2013. "ArcGIS for Server 101: Understanding architecture, deployment, and workflows", https://www.esri.com/ /media/Files/Pdfs/news/arcuser/0313/arc gis101.pdf (13.04.2016).

Mayerle, R., Al-Subhi, A., Fernández Jaramillo, J., Salama, A., Bruss, G., Zubier, K., Runte, K., Turki, A., Hesse, K., Jastania, H., Ladwig, N., Mudarris, M., 2016. Development of a coastal information system for the management of Jeddah coastal waters in Saudi Arabia. Computers \& Geosciences, 89, pp. 7178.

Moore, T., Morris, K., Blackwell, G., Gibson, S., Stebbing, A., 1999. An Expert System for Integrated Coastal Zone Management: A Geomorphological Case Study. Marine Pollution Bulletin, 37, pp. 361-370.

Noujas, V., Thomas, K.V., Badarees, K.O., 2016. Shoreline management plan for a mudbank dominated coast. Ocean Engineering, 112, pp. 47-65.

Peng, Z.R., 1999. An Assessment Framework for the Development of Internet GIS. Environment and Planning B: Planning and Design, 26, pp. 117-132.

Rodríguez, I., Montoya, I., Sánchez, M.J., Carreño, F., 2009. Geographic Information Systems applied to Integrated Coastal Zone Management. Geomorphology, 107, pp. 100-105.

Sahin, K., Gumusay, M.U., 2007. Internet GIS and Its Usage in Forest Fires. Harita Dergisi, 138, pp. 69 - 83.

Tasligil, N., 2004. The Geographical Importance of the Bosphorus Strait, Marmara Geographical Review, 10. 